\title{
Dissipation and Residues of Thiram in Potato and Soil
}

\author{
Shaowen Liu, ${ }^{1,2}$ Aijuan Bai, ${ }^{1}$ Li Zhou, ${ }^{1,3}$ Chuanshan Yu, ${ }^{1}$ Yanjie Li, ${ }^{1}$ \\ Sufang Fan, ${ }^{1}$ and Canping Pan ${ }^{1}$ \\ ${ }^{1}$ Department of Applied Chemistry, College of Science, China Agricultural University, Beijing 100193, China \\ ${ }^{2}$ Hunan Plant Protection Institute, Changsha, Hunan 410125, China \\ ${ }^{3}$ Tea Research Institute, Chinese Academy of Agricultural Sciences, Hangzhou 310008, China
}

Correspondence should be addressed to Canping Pan; canpingp@cau.edu.cn

Received 10 December 2014; Revised 15 March 2015; Accepted 15 March 2015

Academic Editor: David Bongiorno

Copyright (C) 2015 Shaowen Liu et al. This is an open access article distributed under the Creative Commons Attribution License, which permits unrestricted use, distribution, and reproduction in any medium, provided the original work is properly cited.

\begin{abstract}
The residue levels of thiram during potato cultivation in open field were evaluated. Thiram residues were determined by methylation derivation method with high performance liquid chromatography (HPLC). Wettable powder (WP) formulation containing $25 \%$ thiram was applied at $2320 \mathrm{~g}$ active gradient $\mathrm{hm}^{-2}\left(\right.$ a.i. $\left.\mathrm{hm}^{-2}\right)$ dosage for the dissipation study. The decline rate in potato leave and soil followed first-order kinetics equation, and the half-life ranged from 2.8 to 5.4 days and 2.6 to 9.9 days, respectively. In terminal residue, the thiram was sprayed at $580 \mathrm{~g}$ a.i. $\mathrm{hm}^{-2}$ (low concentration, recommended dosage) and $1160 \mathrm{~g}$ a.i. $\mathrm{hm}^{-2}$ (high concentration, double of recommended dosage). The residues of thiram in potato and soil samples collected in the field at preharvest interval of 21 days and 30 days were all below $0.02 \mathrm{mg} \mathrm{kg}^{-1}$. The results show that thiram possesses low dietary risk in potato at harvest according to supervised residue field trial. It may be safe when used at recommended rate of application.
\end{abstract}

\section{Introduction}

Pesticides rank as one of the most important agrochemicals to ensure agricultural production yield and quality. However, they may remain in soil, water, or plants [1] after application. The potential incorporation into the food chain could be a risk for animals and human beings. Thus the decline and residue levels of pesticides after proper application are basic for dietary risk assessment. Thiram is a protective dithiocarbamate fungicide, widely used as a foliar spray on fruits, vegetables, and ornamentals and as seed treatment to control a number of fungal diseases [2]. Oxidation of ferbam and ziram could also generate thiram $[3,4]$. Thiram has a relatively low toxicity, but hand eczema and dermatitis to works [5], adverse reproductive [6-8], developmental effects [7] and neurotoxicity [9] to test animals, and genotoxic activity to cell system $[10,11]$ has been reported. Regarding dithiocarbamate analytical methodology in vegetables, their stability have been reported, especially in acidic plant juices $[12,13]$. Dithiocarbamates easily decompose to carbon disulphide $\left(\mathrm{CS}_{2}\right)$ and the respective amine in acidic medium [14]. For this reason, it is not easy to achieve satisfactory recoveries for thiram $[15,16]$. In consequence, determination of dithiocarbamates has been based on the decomposition product $\mathrm{CS}_{2}$ for its determination by gas chromatography (GC) $[3,14,17-20]$. In order to diminish risk exposure, the terminal residue of applied chemicals in edible portion should not be higher than maximum residue limit (MRL). MRL of thiram in potato is $0.3 \mathrm{mg} \mathrm{kg}^{-1}$ (expressed as $\mathrm{CS}_{2}$ ) set by European Union (EU). Food and Agriculture Organization of the United Nations (FAO) has established MRL for thiram in apple, nectarine, peach, and strawberry. Up to now, there is no MRL set for potato in China due to the lack of information about residue studies, and there was no paper published to report the residue dissipation of thiram in potato under field condition.

In this work, an analytical method based on the methylation derivation and further determined by HPLC-UV was applied to evaluate the decline rate and terminal residues of thiram in potato and soil. In this experiment, 25\% thiram WP was applied to control potato late blight (Phytophthora infestans (Mont.)). The residue data collected from open field trial in potato was useful in dietary intake assessment and establishing MRL in China. 
TABLE 1: The weather condition of experimental sites during the test period.

\begin{tabular}{llccccccccc}
\hline \multirow{2}{*}{ Year } & \multirow{2}{*}{ Site } & \multicolumn{3}{c}{ Temperature $\left({ }^{\circ} \mathrm{C}\right)$} & \multicolumn{3}{c}{ Relative humidity (\%) } & \multicolumn{3}{c}{ Precipitation } \\
& & Max & Min & Av & Max & Min & Av & Mam $(\mathrm{mm})$ & Av $(\mathrm{mm})$ & Total days \\
\hline \multirow{3}{*}{2011} & Hunan & 29.1 & 10.5 & 20.7 & 82.1 & 43.1 & 60.9 & 34.0 & 6.1 & 20 \\
& Beijing & 36.3 & 18.0 & 28.6 & 88.1 & 48.5 & 56.3 & 59.2 & 4.6 \\
& Jiangsu & 27.4 & 10.0 & 21.7 & 85.2 & 57.7 & 67.6 & 41 & 4.3 & 14 \\
\hline \multirow{3}{*}{2012} & Hunan & 29.6 & 17.6 & 22.3 & 80.1 & 55.6 & 64.5 & 34.0 & 2.5 \\
& Beijing & 36.8 & 15.2 & 20.8 & 79.9 & 30.1 & 47.5 & 35.3 & 4.2 \\
& Jiangsu & 37.2 & 16.4 & 31.3 & 96.2 & 58.3 & 76.9 & 118 & 23 \\
\hline
\end{tabular}

Note: the test period of Hunan is from May to June in both 2011 and 2012; the test period of Beijing is from July to August in 2011 and in 2012 it is from August to September; the test period of Jiangsu is from May to June in 2011 and in 2012 it is from July to August; Max: abbreviation of maximum; Min: abbreviation of minimum; Av: abbreviation of average.

TABLE 2: The soil properties of different experimental sites.

\begin{tabular}{lccccc}
\hline Site & Organic carbon content [26, 27] (\%) & $\mathrm{pH}[28]$ & Sand [29] (\%) & Clay [29] (\%) & Silt [29] (\%) \\
\hline Hunan Province & 1.42 & 6.12 & 40.32 & 15.34 & 42.74 \\
Beijing City & 1.56 & 7.28 & 61.95 & 10.15 & 26.88 \\
Jiangsu Province & 1.14 & 5.97 & 52.60 & 12.78 & 37.97 \\
\hline
\end{tabular}

\section{Materials and Methods}

2.1. Chemical. Thiram standard was provided by Institute for the Control of Agrochemicals, Ministry of Agriculture (ICAMA), China, with a certified purity of $98.5 \% .25 \%$ of thiram WP was supplied from China Agricultural University. Acetonitrile was HPLC grade, obtained from DIMA Technology Inc. (Richmond Hill, USA). Deionizated water was obtained from the Milli-Q SP Reagent Water system (Millipore, Bedford, MA, USA). Other reagents (L-cysteine, $\mathrm{Na}_{2}$ EDTA, sodium hydroxide, tetrabutylammonium hydrogen sulfate, hydrochloric acid, hexane, chloroform, 1,2propanediol, methyl iodide, and anhydrous $\mathrm{Na}_{2} \mathrm{SO}_{4}$ ) were analytical grade, purchased from Beijing Chemical Reagents Co. (Beijing, China). Anhydrous $\mathrm{Na}_{2} \mathrm{SO}_{4}$ was baked at $500^{\circ} \mathrm{C}$ for $5 \mathrm{~h}$ before use.

Thiram standard stock solution $500 \mathrm{mg} \mathrm{L}^{-1}$ was prepared in acetonitrile by weighing $0.025 \mathrm{~g}$ of the analyte into a $50 \mathrm{~mL}$ volumetric flask and stored at $-20^{\circ} \mathrm{C}$. Working standard solution was obtained by diluting the stock solution with acetonitrile and stored at $-4^{\circ} \mathrm{C}$ in the dark.

2.2. Field Trial. The open field trial was carried out in Beijing, Hunan, and Jiangsu Province in China from 2011 to 2012. Every site was composed of 24 plots for eight experiment treatments, one of which consisted of three replicate plots. The treatments were designed for decline study for potato leave and soil at high dose, controls for potato leave and soil without thiram spray, terminal residue study at the recommended dose and high dose. Every plot was separated by irrigation channel.

2.3. Decline Study Design. Thiram was sprayed in the experiment at the dosage of $2320 \mathrm{~g}$ a.i. $\mathrm{hm}^{-2}$. Triplicate potato leaf samples were picked from every treated plot and untreated controls randomly before spraying and $0(2 \mathrm{~h}), 1,3,5,7,14$, 28 , and 36 days after foliar application. Soil samples were collected on the top of $10 \mathrm{~cm}$ depth from the experimental plots at the same time as potato leaf, and pebbles and other unwanted materials in soil were removed manually.

2.4. Terminal Residue Study Design. $580 \mathrm{ga}$ a.i. $\mathrm{hm}^{-2}$ and $1160 \mathrm{~g}$ a.i. $\mathrm{hm}^{-2}$ were sprayed two and three times with interval of 7 days. Potatoes were selected randomly and the soil on the potato surface was removed. Soil samples on the top of $10 \mathrm{~cm}$ depth were collected at 21 and 30 days after the last spray.

2.5. Sample Preparation and Storage. Potato leaf was cut into small segments and mixed in a blender. Potatoes were quartered, and subsamples from the opposite quarters were collected and chopped and then homogenized in a blender. Soil sample was air-dried and sieved through $0.45 \mathrm{~mm}$ sieve. All prepared samples were stored at $-20^{\circ} \mathrm{C}$ until analysis.

The weather condition and soil properties of experimental sites during the test period were listed in Tables 1 and 2 . Particle size of soil was obtained from Malvern Marstersizer2000 laser particle size analyzer. The organic carbon content was determined by oxidation with potassium dichromate.

\section{Analytical Procedures}

3.1. Sample Pretreatment. $20 \mathrm{~g}$ blended samples were weighed in a $150 \mathrm{~mL}$ beaker flask and extracted with $0.2 \mathrm{~g}$ of Lcysteine and $40 \mathrm{~mL}$ of $0.25 \mathrm{M}$ EDTA in $0.45 \mathrm{M}$ sodium hydroxide for $15 \mathrm{~min}$ in a shaking air bath at $20^{\circ} \mathrm{C}$ and $150 \mathrm{rpm}$. Spiking was carried out before EDTA solution was added. The extract was transferred to a $100 \mathrm{~mL}$ centrifuge tube and centrifuged for $5 \mathrm{~min}$ at $3800 \mathrm{rpm}$. The supernatant 
was poured into a $250 \mathrm{~mL}$ closed glass flask. The precipitation was extracted with another $40 \mathrm{~mL}$ solution again. $\mathrm{pH}$ of the combined supernatant was adjusted to ca. 7.0 with $2 \mathrm{M} \mathrm{HCl}$ aqueous solution after a solution of ammonium hydrogen sulfate $(0.41 \mathrm{M}, 5 \mathrm{~mL})$ was added. The mixture was shaken vigorously for $10 \mathrm{~min}$, together with $40 \mathrm{~mL}$ of methyl iodide $(0.05 \mathrm{M})$ in chloroform-hexane $(3 / 1 ; \mathrm{v} / \mathrm{v})$ and stood for $20 \mathrm{~min}$. The organic layer separated was centrifuged for $5 \mathrm{~min}$ at $3800 \mathrm{rpm}$, followed by addition of anhydrous sodium sulfate to remove residual water. The organic phase was evaporated to be nearly dry using rotatory evaporator at $30^{\circ} \mathrm{C}$. The residue was constituted with $2 \mathrm{~mL}$ acetonitrile-water (1/1; $\mathrm{v} / \mathrm{v})$, followed by filtration with $0.45 \mu \mathrm{m}$ membrane.

3.2. Chromatographic Conditions. The determination of thiram was carried out with Agilent 1100 series HPLC (Agilent Technologies, USA) coupled with diode array detector (DAD). $\mathrm{A} \mathrm{C}_{18}$ column (Agilent ZORBAX SB-C18 $250 \times$ $4.6 \mathrm{~mm} 5 \mu \mathrm{m}$ ) was employed. The detection wavelength was $272 \mathrm{~nm}$. The mobile phase consisted of acetonitrile and water $(\mathrm{v} / \mathrm{v}=50: 50)$. The flow rate was $1.0 \mathrm{~mL} \mathrm{~min}^{-1}$ with injection volume of $20 \mu \mathrm{L}$. The temperature of column was set at $25^{\circ} \mathrm{C}$. The approximate retention time of thiram was $8.3 \mathrm{~min}$.

3.3. Concentration Conversion from Thiram to $\mathrm{CS}_{2}$. The concentration conversion formula between thiram and $\mathrm{CS}_{2}$ is described as follows:

$$
c_{\mathrm{CS}_{2}}=\frac{c \times k \times M_{\mathrm{CS}_{2}}}{M},
$$

where $c$ is concentration of thiram, $\mathrm{mg} \mathrm{kg}^{-1} ; k$ is conversion coefficient, $k=2 ; c_{\mathrm{CS}_{2}}$ is concentration of $\mathrm{CS}_{2}, \mathrm{mg} \mathrm{kg}^{-1} ; M$ is molar mass of thiram, $240.4 \mathrm{~g} \mathrm{~mol}^{-1}$; and $M_{\mathrm{CS}_{2}}$ is molar mass of $\mathrm{CS}_{2}, 76.1 \mathrm{~g} \mathrm{~mol}^{-1}$.

\section{Results and Discussion}

4.1. Fortified Recovery Results. The analytical method was performed on parameters of linearity, recovery, limit of detection (LOD), and limit of quantification (LOQ). The equation of linear working calibration of S-methylation derivative from thiram was $y=2068 x-23.51, R^{2}=0.998$ in the range of $0.006 \sim 0.95 \mathrm{mg} / \mathrm{kg}$. Recovery studies were conducted by spiking thiram at levels of $0.02,0.04,0.1$, and $0.5 \mathrm{mg} / \mathrm{kg}$. Average recovery of the potato leave, potato, and soil was in the range of $70.3 \% \sim 88.9 \%$, within $14.4 \%$ RSD. The result was parallel with the analysis method reported before [17]. Typical HPLC chromatograms were shown in Figure 1. The LOD set at a signal-to-noise ratio of $3: 1$ were $0.02,0.01$, and $0.01 \mathrm{mg} \mathrm{kg}^{-1}$ in potato leave, potato, and soil. The LOQ was identified as the lowest spiking level, which was $0.04,0.02$, and $0.02 \mathrm{mg} / \mathrm{kg}$ in potato leave, potato, and soil, respectively. The results are shown in Table 3 and Figures 1, 2, and 3.

4.2. Decline Kinetics of Thiram in Potato Plant and Soil. The decline kinetics of thiram in potato leave and soil are presented in Figures 4 and 5 by plotting residue concentration over time and calculated on the basis of equation $\ln C_{t} / C_{0}=$ $-k t$ and $T_{1 / 2}=\ln 2 / k$, where $t$ is the time after pesticide application, $C_{t}$ stands for the residue concentration of the pesticide at time $t, C_{0}$ means an initial concentration after application (at $t=0$ ), $k$ is a decline coefficient, and $T_{1 / 2}$ is defined as the half-life. The results of dissipation equation and half-life were summarized in Table 4 . The half-life of thiram in potato leave and soil was from 3 to 6 days and 3 to 10 days individually under field condition. Moreover, the degradation behavior in potato leave was comparatively more stable with almost the same half-life time in different three sites for two years than that in soil which covered a wide range of halflife time. Compared to the half-life of thiram on tomato fruit (10.3 days), radish leaf (11.3 days) and radish root (5.8 days) [21], paddy plants (1.5-1.8 days) [22], and mushroom (4.2 hours) [23], the varied decay rate of thiram in different crops was perhaps due to growth dilution besides environmental factors. In the case of soil, the decay of thiram was affected by many factors, such as light, heat, $\mathrm{pH}$, moisture, content of clay, and mineral ion [24]. The degradation trial was conducted in July in Beijing and in May in Hunan and Jiangsu. In July, there were the largest rain and the highest temperature in Beijing with strong light intensity that might make thiram decline easier than the other two sites [25]. However, in the 2nd year, namely, 2012, the climate of Jiangsu in July was exceptional. The maximum temperature in the first half of the month was over $35^{\circ} \mathrm{C}$, followed by high rainfall later, so that the half-life of thiram in Jiangsu is shorter in 2012. The result agreed with [21], which revealed that the decay rate of thiram increased with the increase of temperature.

4.3. Terminal Residues of Thiram in Potato and Soil. Terminal residues of thiram in soil were lower than $0.02 \mathrm{mg} / \mathrm{kg}$, while the residual thiram in all potato samples harvested in 21 days and 30 days after spray were not detectable, all of which revealed that the application of thiram during potato cultivation results in low residue in crops and soil.

\section{Conclusions}

In this work, the degradation of thiram under open field condition was studied in two consecutive years in Beijing, Hunan, and Jiangsu. Methylation derivation method to determine thiram with HPLC-UV was validated and applied for residues evaluation in potato leave, potato, and soil. The halflife of thiram in potato leave and soil was 2.8 to 5.4 days and 2.6 to 9.9 days. The final residues in soil were less than $0.08 \mathrm{mg} \mathrm{kg}^{-1}$ at 14 and 21 days after application. In the case of potato, the terminal residue is not detectable when sprayed at 580 and $1160 \mathrm{~g}$ a.i. $\mathrm{hm}^{-2}$ at interval of 7 days for two or three times. Therefore, the results demonstrated that thiram can be used in potato cultivation as a low toxicity pesticide for the environment and human beings.

\section{Conflict of Interests}

The authors declare that there is no conflict of interests regarding the publication of this paper. 
TABLE 3: Recoveries and relative standard deviations (RSD) of fortified samples.

\begin{tabular}{|c|c|c|c|c|c|}
\hline Sample & Fortified level (mg/kg) & Average recoveries (\%) & RSD (\%) & LODs $(\mathrm{mg} / \mathrm{kg})$ & LOQs (mg/kg) \\
\hline \multirow{3}{*}{ Potato leave } & 0.04 & 73.6 & 11.7 & \multirow{3}{*}{0.02} & \multirow{3}{*}{0.04} \\
\hline & 0.1 & 71.0 & 9.9 & & \\
\hline & 0.5 & 70.3 & 13.1 & & \\
\hline \multirow{3}{*}{ Potato } & 0.02 & 78.6 & 6.8 & \multirow{3}{*}{0.01} & \multirow{3}{*}{0.02} \\
\hline & 0.1 & 72.1 & 3.3 & & \\
\hline & 0.5 & 72.4 & 14.4 & & \\
\hline \multirow{3}{*}{ Soil } & 0.02 & 83.4 & 9.3 & \multirow{3}{*}{0.01} & \multirow{3}{*}{0.02} \\
\hline & 0.1 & 88.9 & 3.0 & & \\
\hline & 0.5 & 88.6 & 3.0 & & \\
\hline
\end{tabular}

LOD: limit of detection; LOQ: limit of quantification.

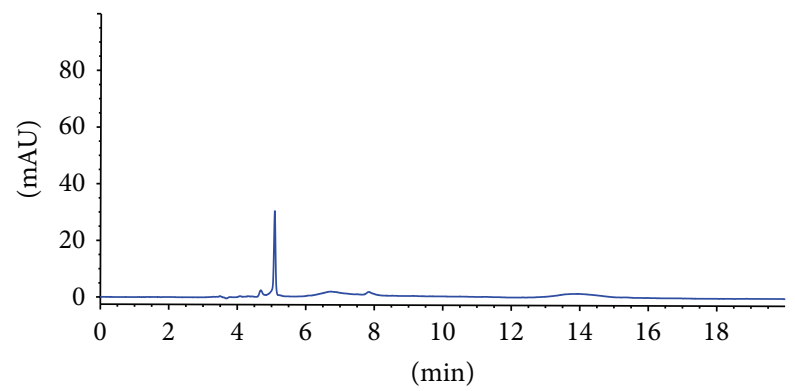

(a)

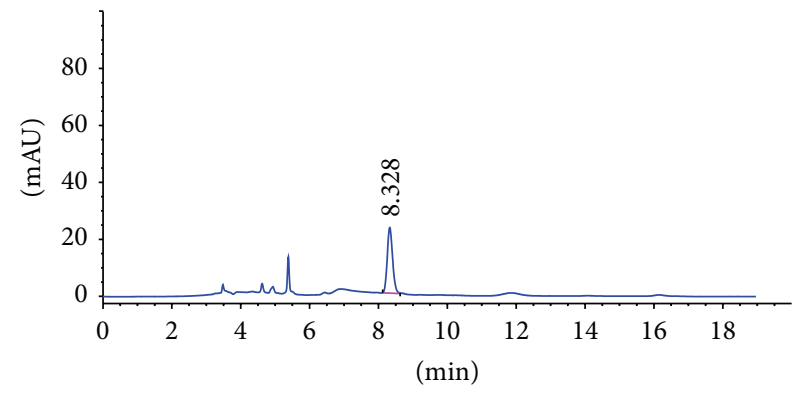

(b)

Figure 1: Chromatograms of blank (a) and fortified level $\left(0.02 \mathrm{mg} \mathrm{kg}^{-1}(\mathrm{~b})\right)$ in soil samples.

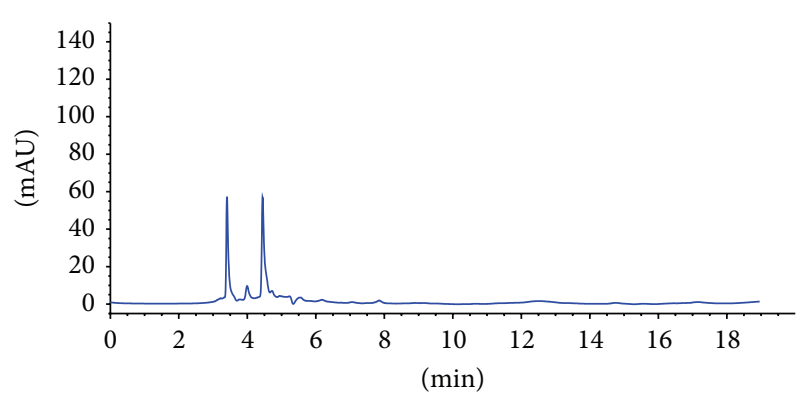

(a)

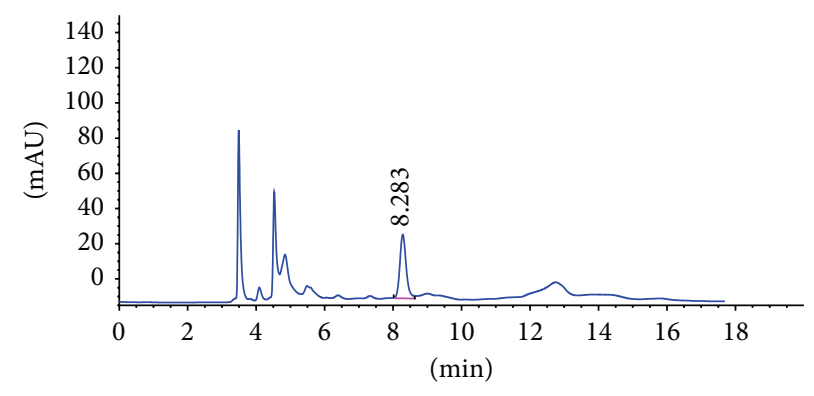

(b)

FIGURE 2: Chromatograms of blank (a) and fortified level $(0.02 \mathrm{mg} / \mathrm{kg}(\mathrm{b}))$ in potato samples.

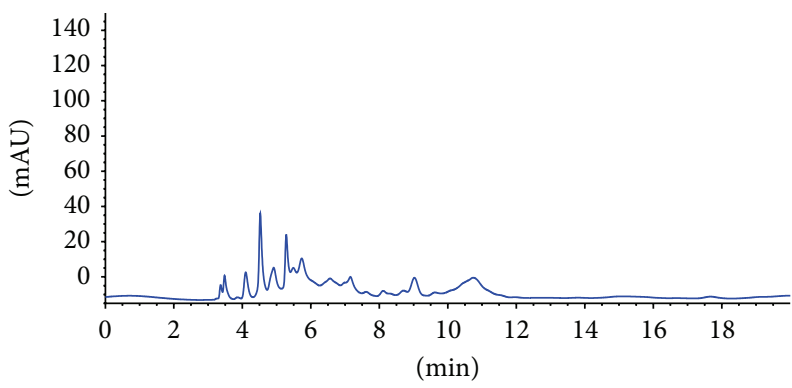

(a)

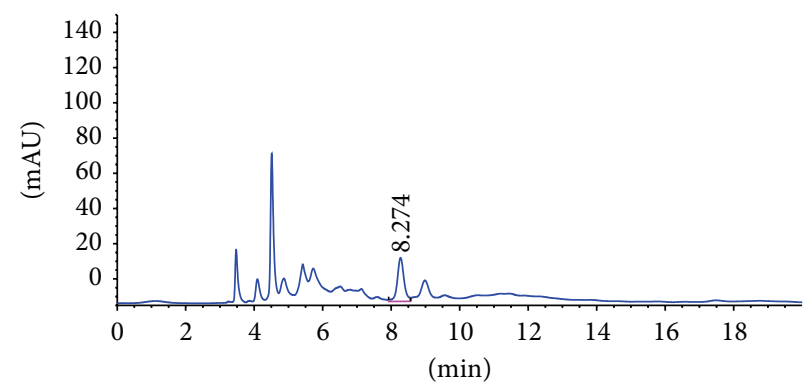

(b)

Figure 3: Chromatograms of blank (a) and fortified level $(0.04 \mathrm{mg} / \mathrm{kg}(\mathrm{b}))$ in potato leave samples. 
TABLE 4: Dissipation in potato leave and soil.

\begin{tabular}{|c|c|c|c|c|c|}
\hline Sample & Time & Sites & Regression equation & The square of correlation coefficient & Half-life (day) \\
\hline \multirow{6}{*}{ Potato plant } & \multirow{3}{*}{ 1st year } & Beijing & $C_{t}=2.423 e^{-0.22 t}$ & $r^{2}=0.631$ & 3.2 \\
\hline & & Hunan & $C_{t}=133.7 e^{-0.16 t}$ & $r^{2}=0.982$ & 4.4 \\
\hline & & Jiangsu & $C_{t}=17.55 e^{-0.17 t}$ & $r^{2}=0.650$ & 4.1 \\
\hline & \multirow{3}{*}{ 2nd year } & Beijing & $C_{t}=7.684 e^{-0.28 t}$ & $r^{2}=0.874$ & 3.9 \\
\hline & & Hunan & $C_{t}=1.697 e^{-0.13 t}$ & $r^{2}=0.697$ & 5.4 \\
\hline & & Jiangsu & $C_{t}=30.39 e^{-0.25 t}$ & $r^{2}=0.817$ & 2.8 \\
\hline \multirow{6}{*}{ Soil } & \multirow{3}{*}{ 1st year } & Beijing & $C_{t}=0.999 e^{-0.27 t}$ & $r^{2}=0.821$ & 2.6 \\
\hline & & Hunan & $C_{t}=2.147 e^{-0.10 t}$ & $r^{2}=0.659$ & 6.9 \\
\hline & & Jiangsu & $C_{t}=0.231 e^{-0.07 t}$ & $r^{2}=0.921$ & 9.9 \\
\hline & \multirow{3}{*}{ 2nd year } & Beijing & $C_{t}=0.257 e^{-0.15 t}$ & $r^{2}=0.991$ & 4.7 \\
\hline & & Hunan & $C_{t}=0.421 e^{-0.08 t}$ & $r^{2}=0.817$ & 8.7 \\
\hline & & Jiangsu & $C_{t}=0.130 e^{-0.22 t}$ & $r^{2}=0.950$ & 3.2 \\
\hline
\end{tabular}

$C_{t}$ : the residue concentration of the pesticide at time " $t$ "; $t$ : the time after pesticide application.



- Beijing, 2011

— Hunan, 2011

•- Jiangsu, 2011

(a)



(b)

FIgURE 4: The decline of thiram in potato leave of Beijing, Hunan, and Jiangsu.

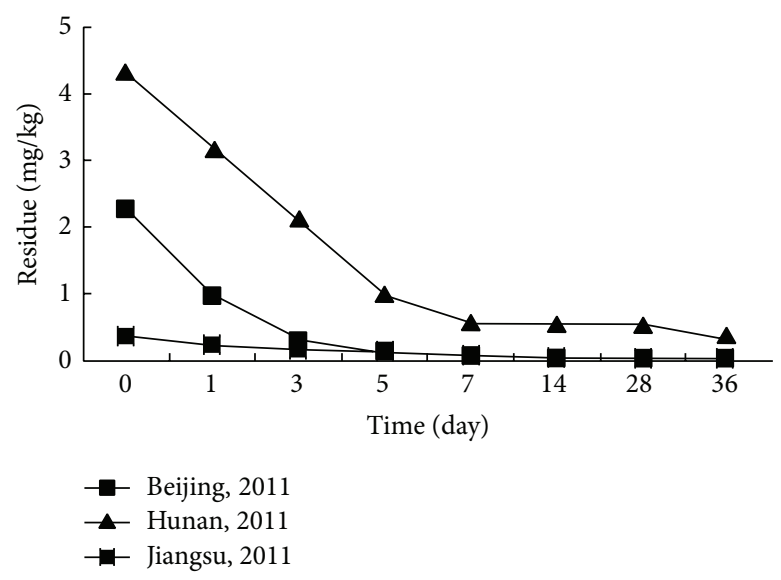

(a)

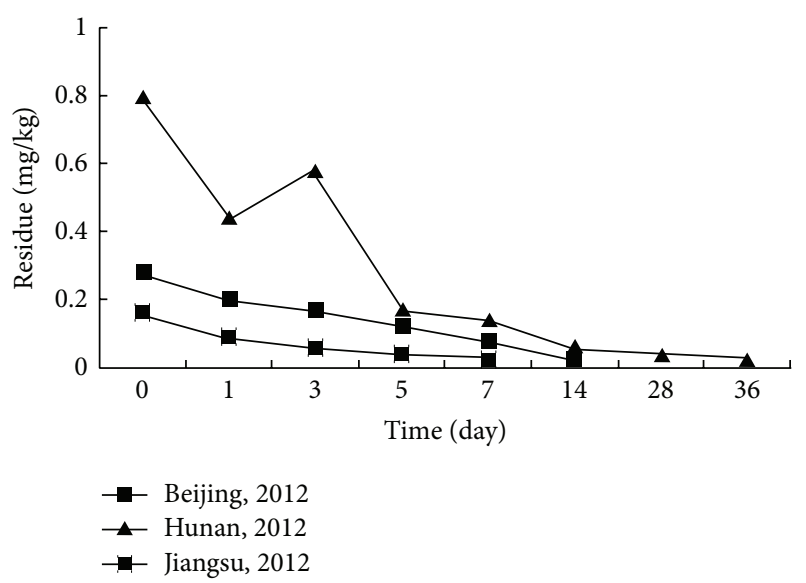

(b)

Figure 5: The decline of thiram in soil of Beijing, Hunan, and Jiangsu. 


\section{Acknowledgments}

This study was partially supported by Chinese National Natural Science Foundation (Project no. 31171872) and Guanxi Special Invited Scientist Fund.

\section{References}

[1] G. C. López-Pérez, M. Arias-Estévez, E. López-Periago, B. SotoGonzález, B. Cancho-Grande, and J. Simal-Gándara, "Dynamics of pesticides in potato crops," Journal of Agricultural and Food Chemistry, vol. 54, no. 5, pp. 1797-1803, 2006.

[2] A. K. Malik and W. Faubel, "Methods of analysis of dithiocarbamate pesticides: a review," Pesticide Science, vol. 55, no. 10, pp. 965-970, 1999.

[3] V. K. Sharma, J. S. Aulakh, and A. K. Malik, "Thiram: degradation, applications and analytical methods," Journal of Environmental Monitoring, vol. 5, no. 5, pp. 717-723, 2003.

[4] S. Walia, R. K. Sharma, and B. S. Parmar, "Isolation and simultaneous LC of thiram and its less toxic transformation prodcuct in DS formuletion," Bulletin of Environmental Contamination and Toxicology, vol. 83, pp. 363-368, 2009.

[5] I. R. Edwards, D. H. Ferry, and W. A. Temple, "Fungicide and related compounds," in Handbook of Pesticide Toxicology, W. J. Hayes and E. R. Laws, Eds., pp. 1436-1469, Academic Press, New York, NY, USA, 1991.

[6] M. H. Prasad, K. Pushpavathi, P. Rita, and P. P. Reddy, “The effect of thiram on the germ cells of male mice," Food and Chemical Toxicology, vol. 25, no. 9, pp. 709-711, 1987.

[7] T. E. Stoker, R. L. Cooper, J. M. Goldman, and J. E. Andrews, "Characterization of pregnancy outcome following thiraminduced ovulatory delay in the female rat," Neurotoxicology and Teratology, vol. 18, no. 3, pp. 277-282, 1996.

[8] V. K. Mishra, M. K. Srivastava, and R. B. Raizada, “Testicular toxicity in rat to repeated oral administration tetramethylthiuram disulfide (Thiram)," Indian Journal of Experimental Biology, vol. 36, no. 4, pp. 390-394, 1998.

[9] K. Maita, S. Tsuda, and Y. Shirasu, "Chronic toxicity studies with thiram in Wistar rats and beagle dogs," Fundamental and Applied Toxicology, vol. 16, no. 4, pp. 667-686, 1991.

[10] M. Zdzienicka, M. Zielenska, B. Tudek, and T. Szymczyk, "Mutagenic activity of thiram in Ames tester strains of Salmonella typhimurium," Mutation Research, vol. 68, no. 1, pp. 9-13, 1979.

[11] R. C. Agrawal, Y. Shukla, and N. K. Mehrotra, "Assessment of mutagenic potential of thiram," Food and Chemical Toxicology, vol. 35 , no. 5, pp. 523-525, 1997.

[12] C. Lesmes-Fabian and C. R. Binder, "Pesticide flow analysis to assess human exposure in greenhouse flower production in Colombia," International Journal of Environmental Research and Public Health, vol. 10, no. 4, pp. 1168-1185, 2013.

[13] S. Heise, H. Weber, and L. Alder, "Reasons for the decomposition of the fungicide thiram during preparation of fruit and vegetable samples and consequences for residue analysis," Journal of Analytical Chemistry, vol. 366, no. 8, pp. 851-856, 2000.

[14] G. Crnogorac and W. Schwack, "Residue analysis of dithiocarbamate fungicides," TrAC-Trends in Analytical Chemistry, vol. 28, no. 1, pp. 40-50, 2009.

[15] S. J. Lehotay, A. de Kok, M. Hiemstra, and P. van Bodegraven, "Residues from 229 pesticides in fruits and vegetables using gas and liquid chromatography and mass spectrometric detection," Journal of AOAC International, vol. 88, pp. 595-614, 2005.

[16] P. Payá, M. Anastassiades, D. Mack et al., "Analysis of pesticide residues using the Quick Easy Cheap Effective Rugged and Safe (QuEChERS) pesticide multiresidue method in combination with gas and liquid chromatography and tandem mass spectrometric detection," Analytical and Bioanalytical Chemistry, vol. 389, no. 6, pp. 1697-1714, 2007.

[17] E. D. Caldas, M. H. Conceição, M. C. C. Miranda, L. C. K. R. de Souza, and J. F. Lima, "Determination of dithiocarbamate fungicide residues in food by a spectrophotometric method using a vertical disulfide reaction system," Journal of Agricultural and Food Chemistry, vol. 49, no. 10, pp. 4521-4525, 2001.

[18] A. K. Malik and W. Faubel, "Methods of analysis of dithiocarbamate pesticides: a review," Pesticide Science, vol. 55, no. 10, pp. 965-970, 1999.

[19] O. H. J. Szolar, "Environmental and pharmaceutical analysis of dithiocarbamates," Analytica Chimica Acta, vol. 582, no. 2, pp. 191-200, 2007.

[20] Z. Vryzas, E. N. Papadakis, and E. Papadopoulou-Mourkidou, "Microwave-assisted extraction (MAE)-acid hydrolysis of dithiocarbamates for trace analysis in tobacco and peaches," Journal of Agricultural and Food Chemistry, vol. 50, no. 8, pp. 2220-2226, 2002.

[21] B. Gupta, M. Rani, and R. Kumar, "Degradation of thiram in water, soil and plants: a study by high-performance liquid chromatography," Biomedical Chromatography, vol. 26, no. 1, pp. 69-75, 2012.

[22] H. Li, R. Yang, W. Jiang, and Z. Wang, "Residue dynamics of thiram in rice and paddy soil," Pesticide Science and Administration, vol. 30, no. 2, pp. 26-29, 2009.

[23] H. Wang, C. Chen, J. Hu, X. Chen, and J. Li, "Research on residues of chlorothalonil and thiram in mushroom," Chinese Journal of Pesticide Science, vol. 8, pp. 283-287, 2009.

[24] I. Kaur, R. P. Mathur, and S. N. Tandon, "Parameters affecting the decay of some organophosphorus pesticides: a study by high-performance liquid chromatography," Biomedical Chromatography, vol. 11, no. 1, pp. 22-24, 1997.

[25] S. Kaneco, N. Li, K.-K. Itoh, H. Katsumata, T. Suzuki, and K. Ohta, "Titanium dioxide mediated solar photocatalytic degradation of thiram in aqueous solution: kinetics and mineralization," Chemical Engineering Journal, vol. 148, no. 1, pp. 5056, 2009.

[26] M. Arias-Estévez, B. Soto-González, E. López-Periago, B. Cancho-Grande, and J. Simal-Gándara, "Atrazine sorption dynamics in acid-surface soils," Bulletin of Environmental Contamination and Toxicology, vol. 75, no. 2, pp. 264-271, 2005.

[27] China National Environmental Monitoring Centre, Determination of $\mathrm{pH}$ in Soil (Electrode Method), Modern Analysis Method of Soil Elements, China Environmental Science Press, 1992.

[28] China Standard, "Detection of soil, part 3: determination of soil mechanical composition," Tech. Rep. NY/T 1121.3, 2006.

[29] China Standard, Detection of soil, part 6: the determination of soil organic matter, NY/T 1121.3-2006, 2006. 

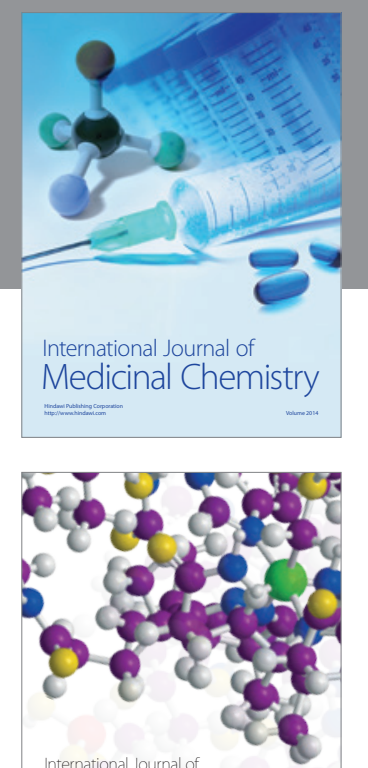

\section{Carbohydrate} Chemistry

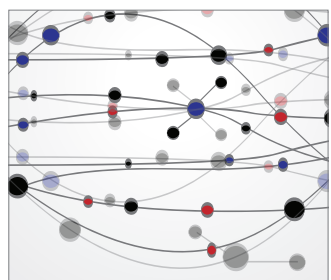

The Scientific World Journal

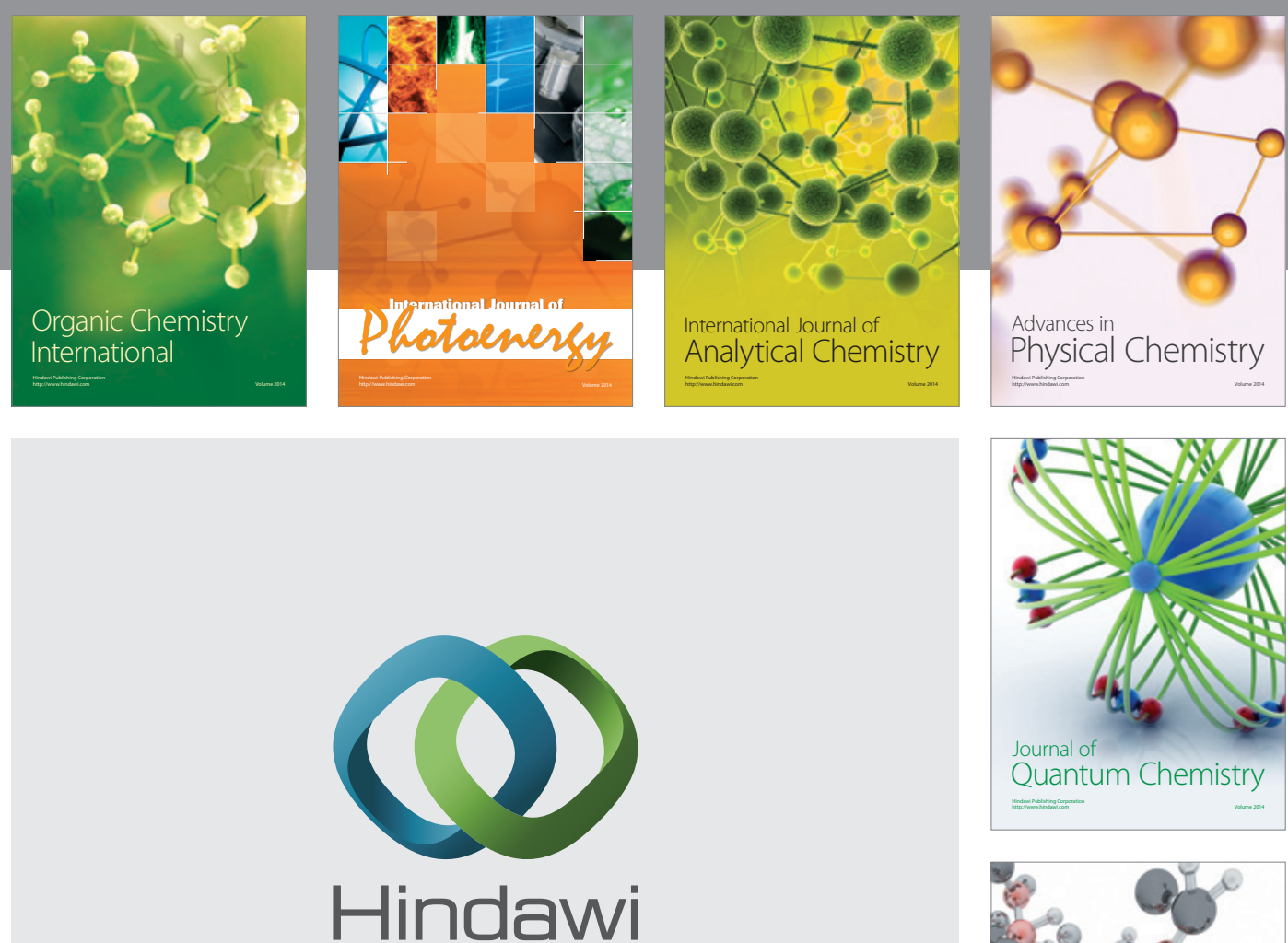

Submit your manuscripts at

http://www.hindawi.com

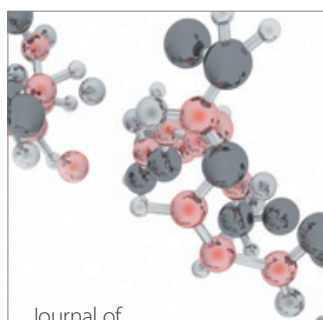

Analytical Methods

in Chemistry

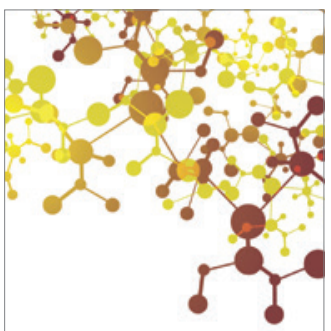

Journal of

Applied Chemistry



Inorganic Chemistry
